\title{
REFLEXÕES SOBRE A MODELAGEM COMO ESTRATÉGIA DE ESTUDO: RELATOS DE DUAS INVESTIGAÇÕES COM ESTUDANTES DE GRADUAÇÃO E PÓS-GRADUAÇÃO
}

\author{
Stefanie Freitas \\ Cristina Capparelli Gerling
}

\section{Resumo}

Neste texto apresentamos os relatos de duas investigações baseadas na modelagem como ferramenta de desenvolvimento musical e pianístico de estudantes em níveis acadêmicos distintos. No primeiro estudo delineamos os resultados de três estudos de caso de estudantes de graduação e no segundo discutimos os resultados com uma amostra de nove participantes vinculados à graduação e à pós-graduação em música da UFRGS. A hipótese proposta de modelagem induzida foi confirmada. Nas duas amostras, a modelagem estimulou a ampliação de recursos expressivos e o desenvolvimento de ideias artísticas individualizadas, além de fornecer estratégias de manipulação de parâmetros temporais no estudo do instrumento.

\section{Palavras-chave:}

Modelagem; Prática Deliberada; Parâmetros Temporais.

\section{INTRODUÇÃO}

O desenvolvimento acelerado da tecnologia e dos meios de comunicação no século $X X$ possibilitou que os mais variados registros fonográficos se tornassem disponíveis em todo o mundo. Com as oportunidades oferecidas pelo rádio, televisão e, mais recentemente, pela internet, gravações de variados gêneros musicais se tornaram facilmente acessíveis. A evolução dos serviços de compartilhamento de mídia na internet permitiu que os consumidores do mercado fonográfico tenham acesso a grandes acervos de música em formatos facilmente armazenados. Como exemplos atuais desses serviços temos o youtube, grooveshark, spotify, entre outros.

Segundo as reflexões de Johnson (2002), a facilidade de acesso às gravações faz com que,

\section{Abstract}

This text presents reports on two modes of investigation using modeling as a learning tool for the musical and pianistic development of students at differing levels of academic ranking. The first part delineates the results of three case studies with undergraduate students and the second part presents results of nine undergraduate and graduate participants from UFRGS. In both cases our initial hypothesis concerning modeling was confirmed as a means to enhancing expressive resources and developing individualized artistic ideas. In addition, modeling seems to promote the use of strategies for the manipulation of temporal parameters during instrumental practice.

Keywords:

Modeling; Deliberate Practice; Temporal Parameters.

consciente ou inconscientemente, algumas destas se tornem modelos de interpretação. Ao ouvirmos passagens de virtuosidade, nem sempre nos damos conta que o intérprete precisou de tempo e de alguns takes para que fosse possível alcançar tal nível de perfeição. Uma vez gravada, a reprodução se torna imutável e passa a fornecer um produto musical de valor comprovado para os intérpretes e seu público, bem como para os estudantes e professores de música.

As interpretações são um tipo de realização possível para um determinado intérprete em uma determinada ocasião e representam escolhas feitas a partir da notação musical. A notação musical codifica alturas, durações, articulações, dinâmicas e andamentos. A partir da decodificação destes parâmetros definimos elementos expressivos e deliberamos a projeção das 
decisões de colorido, agógica e gestualidade. Estes elementos podem estar sugeridos, mas não estão explícitos na partitura.

É através de gravações que podemos ouvir o concerto para piano de Schumann e imediatamente identificar a interpretação de Martha Argerich ou, da mesma forma, podemos reconhecer Artur Rubinstein interpretando as Polonaises de Chopin logo nos primeiros compassos. A escuta de gravações como parte da preparação de uma interpretação é uma prática bastante disseminada. Podemos ouvir gravações para entender como outros músicos compreendem determinada obra e observar quais decisões interpretativas foram tomadas. Da mesma forma que compositores recebem influências composicionais de seus mestres modelando-se em suas obras, nós, intérpretes, ao observarmos criticamente as gravações por nós selecionadas, também recebemos influências interpretativas.

O processo de aprendizagem do jazz através da escuta e imitação de gravações tem sido objeto de estudo. Berliner (1994) identifica três estágios no desenvolvimento da obtenção de habilidades no jazz: imitação, assimilação e inovação. $O$ autor analisa as técnicas específicas utilizadas no desenvolvimento de uma voz artística individualizada e a libertação da sombra dos grandes mestres e improvisadores do jazz. Nesse estudo sobre a assimilação das convenções estilísticas do gênero, fazem parte do processo a transcrição, a imitação e a análise dos solos do repertório standard desse gênero. Berliner destaca a internalização de motivos, frases e solos como processo para a construção de um arquivo direcionado à criação de melodias originais. Trazendo para a tradição da música europeia ocidental chamada erudita ou de concerto, podemos acompanhar o raciocínio de outro notável pesquisador. Para Repp, “(...) a imitação é um primeiro estágio necessário em um desenvolvimento que, idealmente, deve conduzir à assimilação dos padrões imitados com a aquisição de um rico vocabulário expressivo dos quais combinações e padrões novos e originais podem emergir"1 (REPP, 2000, p.208). O autor afirma que a imitação deliberada de estilos expressivos de grandes artistas do passado, realizada como um exercício, pode ajudar a desenvolver um vocabulário expressivo mais abrangente.
Em direção oposta à ideia de que através da imitação o estudante pode perder sua originalidade, a imitação reflexiva ou modelagem, como exercício e não como propósito final, estimula a reflexão sobre o processo de aprendizagem e sobre 0 desenvolvimento dos seus próprios recursos interpretativos. Dessa forma, o estudante pode selecionar os elementos que Ihe pareçam mais adequados ou atraentes e pode ir além ao criar novas alternativas interpretativas sustentadas pelo conhecimento amplo do que foi feito por renomados pianistas. Schön (1987) comenta que "ao buscar conscientemente a maneira pela qual os mestres projetam [a execução], o estudante aumenta a sua gama de possibilidades interpretativas e expande sua liberdade de escolha"2 (SCHÖN, 1987, p.121).

\section{A MODELAGEM COMO ESTRATÉGIA DE ENSINO/ESTUDO}

Uma das estratégias tradicionais utilizadas para ensinar um estudante como uma obra musical deve ser executada é a modelagem (DICKEY, 1992). A modelagem ${ }^{3}$ no âmbito musical é o processo de aprendizagem pelo qual o estudante escuta interpretações que the servem de modelo, procura imitar, absorve ou replica elementos interpretativos e, eventualmente, transcende essa fase transformando o que absorveu em ideias interpretativas próprias. Com isso, potencializa seu vocabulário expressivo e permanece próximo da tradição artística de interpretação (FREITAS, 2013).

Tradicionalmente é o professor que demonstra para seu aluno como uma obra deve soar e esta prática encontra-se disseminada e absorvida no processo de ensino. Ao utilizar a modelagem como estratégia de ensino de recursos expressivos, o professor toca ao instrumento ou canta um trecho da obra que está ensinando. Ao imitar seu professor, que representa o modelo, o estudante adquire ferramentas expressivas para criar sua própria interpretação original (WOODY, 1999). A execução do professor ou de um intérprete renomado oferece possíveis modelos para que o aprendiz construa sua própria interpretação.

Podemos conectar esse pensamento à ideia do métodoSuzuki, quesedirecionaparaaaprendizagem musical seguindo os caminhos da aprendizagem da língua materna. Kendall (1985) cita em seu livro alguns trechos do discurso de Shinichi Suzuki no Festival Nacional ocorrido no ano de 1958 em 
Tóquio, Japão: “Devemos reconhecer o incrível poder da criança que absorve tudo ao seu redor e acrescenta ao seu conhecimento"4 (KENDALL, 1985, p.12). Crianças aprendem idiomas através da participação de um processo comunicativo. Elas ouvem todos os tipos de discursos que os adultos oferecem e, através dessas interações, adquirem um vocabulário linguístico e desenvolvem padrões para se comunicar. Costuma-se dizer que a fluência em um idioma é alcançada quando podemos nos expressar de maneira apropriada para cada situação. Em relação à música, podemos dizer que professores devem habilitar os estudantes a se comunicarem musicalmente, a se expressarem artisticamente. De acordo com o método Suzuki (MILLS \& MURPHY, 1973), o ato da escuta musical é um dos elementos mais importantes para o aprendizado em música e pode ser tanto uma fonte de motivação para iniciantes quanto de criatividade para estudantes de nível mais avançado ou mesmo para profissionais. Tanto o próprio professor quanto as gravações fornecem alternativas interpretativas que estimulam a audição, a formação de possíveis modelos e a reflexão sobre a atuação como praticante dessa arte.

\section{ESTUDOS SOBRE MODELAGEM}

Em relação às habilidades expressivas, estudos comprovam que professores utilizam com frequência metáforas (BARTEN, 1998), modelagem (DICKEY, 1992), emoções sentidas (WOODY, 2000) e instruções verbais (WOODY, 1999) para obter resposta (feedback) dos alunos. Vendo que esta é uma questão crucial no ensino, Lindström, Juslin, Bresin e Williamon (2003) delinearam as três referidas estratégias utilizadas no desenvolvimento do aspecto expressivo em estudantes de música. A metáfora é o método mais comumente empregado pelos professores e estudantes aprendem a partir de descrições baseadas em analogias. A alternativa de evocar emoções sentidas baseia-se em evocação de sentimentos e afetos previamente vivenciados pelo próprio aluno como apoio para ambiente ou atmosfera a ser criado na sua execução. Em terceiro lugar, a modelagem auditiva requer que o estudante aprenda a partir da imitação de interpretações, sejam estas do professor ou de outro intérprete. Os autores verificaram como estas três abordagens ou situações se aplicam em uma amostra de 135 alunos de conservatórios europeus: metáforas $81 \%$, emoções sentidas $71 \%$, modelagem auditiva $70 \%$.
Além disso, os 59 alunos que experimentaram os três métodos tendem a preferir metáforas (46\%) a emoções sentidas (34\%) e a modelagem auditiva (15\%). Apesar de o estudo demonstrar que o método da modelagem auditiva é o menos atrativo para esses estudantes, a modelagem é uma estratégia frequentemente defendida por pesquisadores (TAIT, 1992), podendo ser utilizada na prática individual.

Em uma revisão das estratégias de ensino e de aprendizagem, Tait (1992) chega à conclusão que a modelagem pode afetar de forma significativa a qualidade do aprendizado. Segundo Woody (1999), a modelagem contribui especificamente para o aprendizado de recursos de expressividade. Sloboda (1983) defende que as habilidades expressivas podem ser aprendidas e desenvolvidas. Através da imitação, estudantes de música aprendem quais tipos de variações expressivas são apropriadas ou até mesmo exigidas em diferentes contextos. Mais recentemente, Sloboda (1996) concluiu que experts desenvolvem grande parte de suas habilidades expressivas através da imitação de modelos. Os modelos aurais em forma de gravações também podem ser efetivos no incremento das dimensões expressivas na performance (ROSENTHAL, 1984; ROSENTHAL, WILSON, EVANS, \& GREENWALT, 1988).

\section{DELINEAMENTO DAS INVESTIGAÇÕES ACERCA DA MODELAGEM}

Apesar da tradição e do reconhecimento tácito da importância do processo da modelagem como estratégia de ensino em música, esse recurso é pouco explorado como técnica de aprendizagem formal. Esse assunto tende a ser evitado e considerado como impróprio para estudantes de música devido ao medo da imitação como procedimento sem reflexão. Transpondo o senso comum, decidimos então investigar empiricamente a modelagem como ferramenta de ensino e aprendizagem no desenvolvimento musical e pianístico.

\subsection{PRIMEIRO DELINEAMENTO: TRÊS BACHARELANDOS EM PIANO}

O primeiro estudo foi delineado com base em três estudos de caso. Três alunos de piano que cursavam - Bacharelado em Música/Piano na UFRGS se ofereceram voluntariamente para participar. Eram alunos de professores diferentes e estavam 


\begin{tabular}{|c|c|c|}
\hline $\begin{array}{c}\text { MIGUEL } \\
\left(\mathbf{2}^{\circ} \text { semestre }\right)\end{array}$ & $\begin{array}{c}\text { RICHARD COOPER } \\
\left(\mathbf{4}^{\circ} \text { semestre }\right)\end{array}$ & $\begin{array}{c}\text { ADRIAN } \\
\left(\mathbf{6}^{\circ} \text { semestre }\right)\end{array}$ \\
\hline $\begin{array}{c}\text { Frédéric Chopin } \\
\text { Noturno op.48 } N^{\circ} 1\end{array}$ & $\begin{array}{c}\text { Franz Schubert } \\
\text { Improviso op.90 } N^{\circ} 3\end{array}$ & $\begin{array}{c}\text { Robert Schumann } \\
\text { Cenas Infantis op.15 }\end{array}$ \\
\hline $\begin{array}{c}\text { Artur Moreira Lima } \\
\text { http://www.youtube.com/watch?v=Q } \\
\text { mF2F8YBU3E }\end{array}$ & $\begin{array}{c}\text { Alfred Brendel } \\
\text { http://www.youtube.com/watch?v= } \\
\text { GkX4MyDeIqI }\end{array}$ & $\begin{array}{c}\text { Martha Argerich } \\
\text { http://www.youtube.com } / \text { watch?v } \\
=\text { wY fq6jM1c-8 }\end{array}$ \\
\hline
\end{tabular}

Tabela 1 - Informações sobre os participantes, peça escolhida do repertório e modelos a serem imitados.

Fonte: Acervo de Stefanie Freitas e Cristina Capparelli Gerling.

cursando semestres distintos: segundo, quarto e sexto semestre do curso de Bacharelado. A coleta de dados ocorreu durante o semestre acadêmico de $2011 / 2$. A participação constou de entrevistas semiestruturadas e gravações de uma obra do repertório em estudo. Cada um dos participantes foi estimulado a escolher dois trechos contrastantes de uma mesma obra no seu repertório no semestre em questão. Um trecho foi escolhido em função de estar razoavelmente entendido e resolvido. O segundo trecho foi escolhido por apresentar dificuldades ainda intransponíveis à época da coleta. Como parte integral do estudo, cada participante foi instruído a imitar esses dois trechos da gravação de um determinado pianista de renome internacional na sua execução da peça em questão.

Os relatos coletados nas entrevistas contemplaram os depoimentos sobre a preparação do repertório estudado e sobre as gravações dos pianistas consagrados escolhidos nesta modelagem. Foram realizadas três gravações em MIDI no Disklavier Yamaha DKC - 800 durante a última semana de outubro, a última de novembro e na segunda semana de dezembro de 2011. Nas gravações estão registrados os dois trechos de cada um dos três participantes.

Logo após a primeira gravação dos dois trechos da obra escolhida sugerimos que cada participante observasse uma gravação compartilhada e acessível através do site www.youtube.com. Essas gravações foram selecionadas a partir do renome do pianista e foram sugeridas como modelo, estímulo e referência. Para cada participante escolhemos um determinado pianista de acordo com os relatos obtidos durante a primeira entrevista. Priorizamos gravações que não fossem as preferidas dos participantes e demos preferência aos pianistas que pudessem gerar divergências interpretativas (vide Tabela 1$)^{5}$.

Cada participante foi instruído a assistir ao vídeo correspondente com o objetivo de realizar uma imitação dos trechos selecionados. Realizamos a segunda gravação na última semana de novembro de 2011 juntamente com a terceira entrevista, observando a recepção ao estímulo e analisando o processo de estudo com modelagem. Após as seções dedicadas à segunda gravação, os participantes voltaram a estudar da forma como estavam habituados, isto é, sem o recurso da modelagem. Procedemos então à terceira gravação com os dois trechos interpretados de acordo com escolhas pessoais. Foi realizada então a quarta entrevista, logo após a terceira gravação, para discutir sobre as implicações da modelagem no estudo e nas ideias interpretativas de cada participante.

A análise dos dados baseou-se nos relatos sobre as preocupações referentes aos trechos escolhidos, na reflexão do processo de estudo para a modelagem, na observação das características de suas interpretações após a modelagem e na análise do andamento e da condução do tempo musical. Para a análise e construção dos gráficos foram

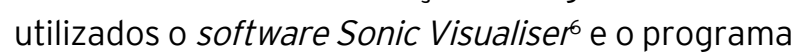




\begin{tabular}{|c|c|}
\hline $\begin{array}{c}\text { Intérpretes do trecho 2 } \\
\text { (c.1-8) }\end{array}$ & $\begin{array}{c}\text { Andamento médio (BPM) } \\
\text { Argerich }\end{array}$ \\
\hline Adrian P1 & 87.4960 \\
\hline Adrian P2 & 84.0016 \\
\hline Adrian P3 & 85.3942 \\
\hline
\end{tabular}

Tabela 2 - Média de andamentos das três gravações de Adrian comparada ao modelo. Fonte: Acervo de Stefanie Freitas e Cristina Capparelli Gerling.

Exce $/$. Em todas as gravações assinalamos cada tempo para analisar a condução do tempo entre cada batida (BPM).

\subsubsection{DISCUSSÃO DOS CASOS}

O participante Richard Cooper declarou ter sentido a influência do modelo no trecho que ele se sentia confortável e seguro de suas ideias. Este já havia tomado algumas decisões interpretativas, mas ao ouvir e imitar a gravação de Brendel, refletiu sobre alguns elementos distintos de sua interpretação. Esse participante chegou à conclusão de que não havia tomado decisões interpretativas para esse trecho de forma tão sistemática quanto pensava e, neste caso específico, o modelo o ajudou a estabelecer suas decisões de forma ainda mais consistente.

O participante Adrian declarou que costuma ouvir várias gravações de pianistas renomados após a definição das suas próprias ideias interpretativas para a peça que começou a estudar. Ao iniciar o estudo de uma obra, ele nos contou que se preocupa com um caráter ou afeto que quer passar aos seus ouvintes. Ao escolher o trecho inseguro para o trabalho de modelagem, justificou sua escolha pelos problemas de compreensão na tradução do título da peça Glückes Genug das Cenas Infantis op.15 de Schumann. Durante o processo de modelagem percebeu estar equivocado quanto ao tipo de dificuldades que encontrava na sua própria execução. Ao analisar os dados das gravações juntamente com seus depoimentos após a imitação do modelo, observamos que os problemas por ele identificados como sendo de ordem técnica eram de fato relacionados ao fraseado e à fluência. Com relação ao trecho 2 , a influência do processo de modelagem pôde ser observada através da média dos andamentos de suas gravações (P1, P2 e P3). A cada gravação, a média de tempo foi se elevando até tornar-se mais rápida do que o próprio modelo (vide Tabela 2) e adequada ao caráter da obra.

Ao observar o desempenho do segundo participante, verificamos que não se deixou influenciar no trecho seguro da obra escolhida (Von fremden Ländern und Menschen). Ele declarou que continuou interpretando o trecho como havia planejado antes da audição. De fato, essa constatação fica evidenciada através do Gráfico 1 que apresenta linhas de condução de tempo completamente distintas do modelo.

Enquanto Richard Cooper afirmou ter sido influenciado pelo modelo principalmente no primeiro trecho, Adrian declarou não ter absorvido nenhum elemento musical do modelo no trecho que estava seguro. No entanto, os dois reconheceram influências do modelo no segundo trecho.

No decorrer do experimento, tornou-se clara a influência que o professor do participante Miguel exerce sobre o aluno. Em um comportamento diverso dos demais participantes, este relatou que a escuta de gravações faz parte do seu processo de estudo não como uma busca por interpretações distintas, mas pelo reconhecimento da obra em um primeiro contato, para ter uma ideia geral. Tendo 


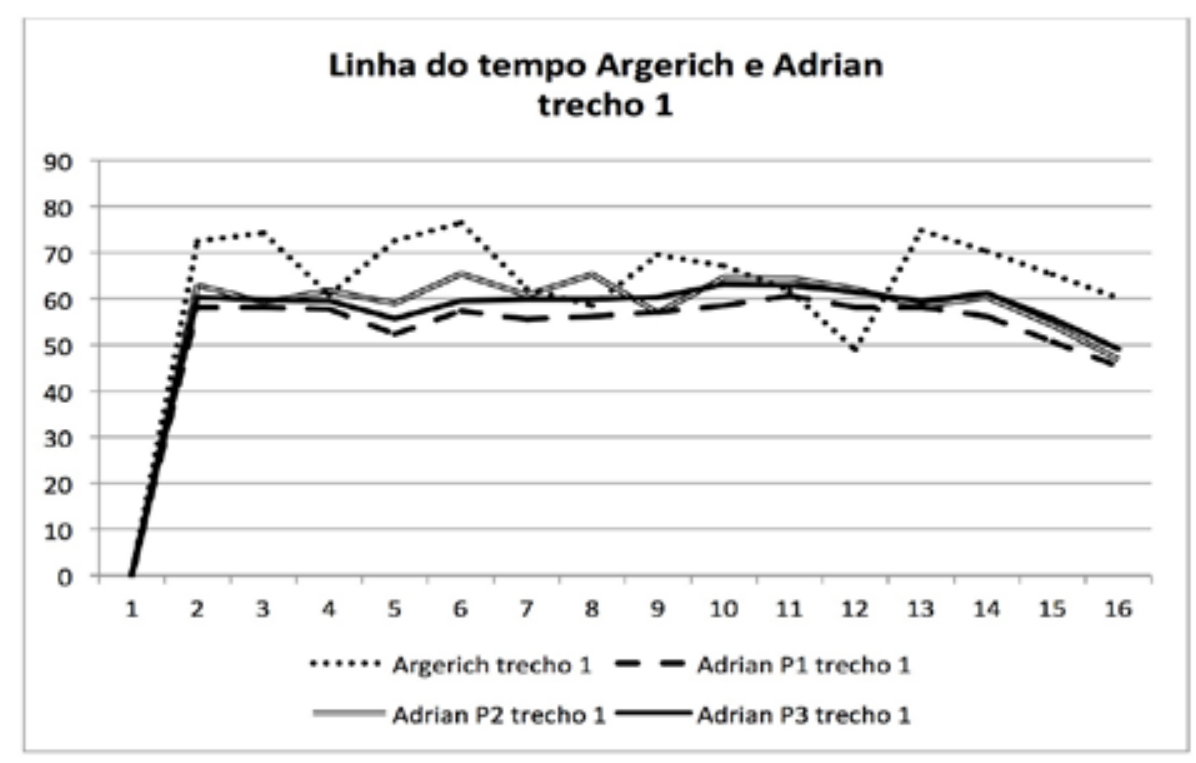

Gráfico 1 - Linha da condução de tempo das três gravações de Adrian e do modelo. Fonte: Acervo de Stefanie Freitas e Cristina Capparelli Gerling.

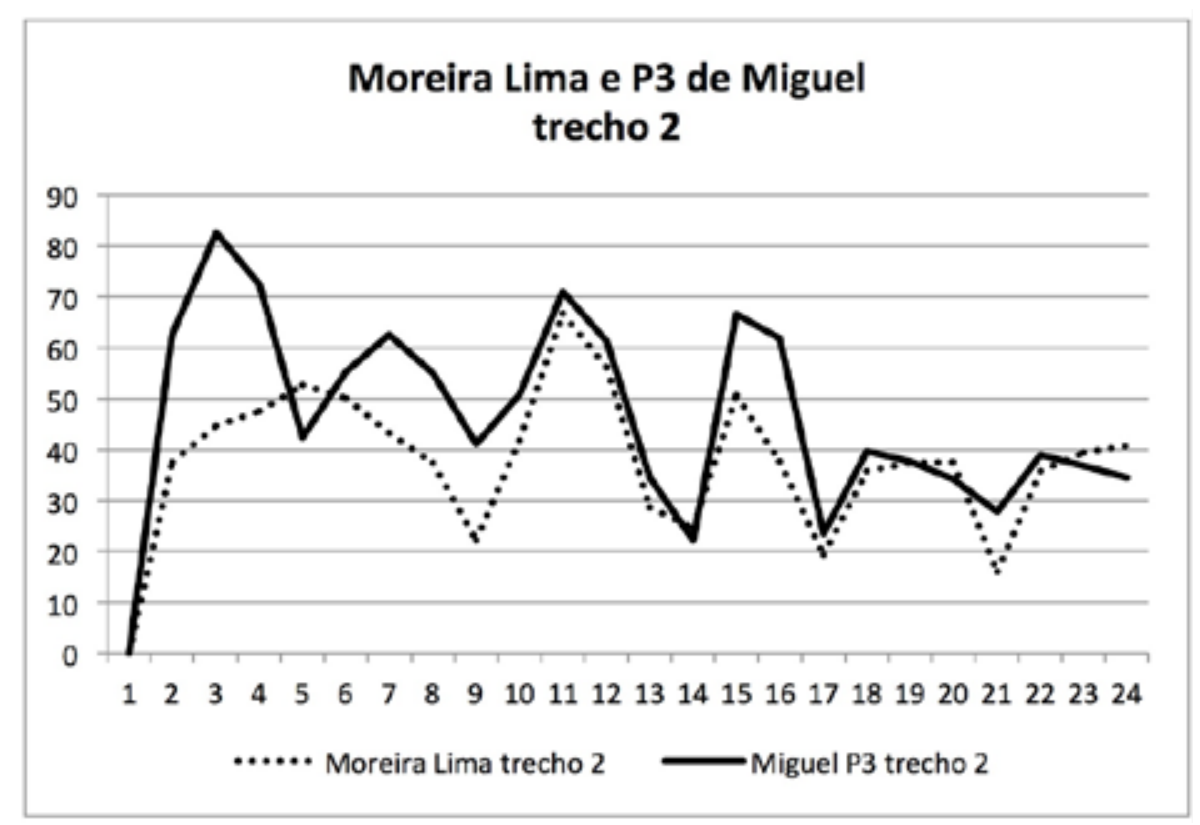

Gráfico 2 - Linha da condução de tempo da última gravação de Miguel e do modelo. Fonte: Acervo de Stefanie Freitas e Cristina Capparelli Gerling. 


\begin{tabular}{|c|c|}
\hline $\begin{array}{c}\text { Intérpretes do trecho 2 } \\
\text { (c.72-77) }\end{array}$ & Andamento médio (BPM) \\
\hline Moreira Lima & 41.3214 \\
\hline Miguel P1 & 44.6245 \\
\hline Miguel P2 & 43.2273 \\
\hline Miguel P3 & 52.4283 \\
\hline
\end{tabular}

Tabela 3 - Média de andamentos das três gravações do segundo trecho de Miguel comparada ao modelo. Fonte: Acervo de Stefanie Freitas e Cristina Capparelli Gerling.

selecionado três trechos do Noturno op.48 N) 1 de Chopin para realizar as gravações, declarou se sentir seguro de suas ideias em dois deles: o primeiro trecho, constituído pelos oito primeiros compassos de abertura (c.1-8), e o segundo trecho (c.49-56, doppio movimento), o "início da terceira parte do Noturno", como explicado na sua entrevista. A análise de dados mostrou que ele não se deixou influenciar pelo modelo. Pudemos detectar traços de semelhanças na condução do tempo e maior fluidez dos trechos na terceira gravação. No entanto, não foi possível constatar a absorção de elementos interpretativos fortemente relacionados à gravação de Moreira Lima. 0 próprio participante considerou a imitação do trecho 1 (início) como um "desastre" e deixou transparecer claramente seu desconforto com o processo. Em relação ao outro trecho bem resolvido, o trecho 1 (doppio movimento), comentou de forma positiva o que chamou de "coerência na interpretação" de Moreira Lima. Mesmo assim, não absorveu quaisquer elementos interpretativos porque não considerou que o modelo forneceu elementos convincentes para sua própria interpretação.

A escolha do trecho inseguro justifica-se porque foi descrita pelo participante como um "final interrogativo". Para ele, essa passagem parecia ter ideias "incompletas e indefinidas". Assim como nos trechos descritos como seguros, seus andamentos não nos deixaram convictas de elementos absorvidos do modelo ou de algum tipo específico de influência. Neste caso, seus andamentos apresentaram melhora na fluidez do trecho em questão, refletindo uma maior segurança na performance realizada para as gravações (vide Tabela 3)

Já o gráfico comparativo da terceira gravação de Miguel e da gravação do modelo apresentou uma sobreposição de linhas (vide Gráfico 2). Esta sobreposição aponta para uma quase exatidão na condução do tempo da cadência $V-I$ do final do Noturno (c.74-75). Apesar da ausência de evidências mais nítidas de uma possível influência do modelo, devemos destacar seus depoimentos sobre o papel do modelo em sua última gravação. o participante declarou que na falta de ideias interpretativas pré-estabelecidas, absorveu sim, ainda que de forma inconsciente, algumas ideias do modelo. Através dos depoimentos e da análise de suas gravações, concluímos que este ampliou seu vocabulário expressivo de forma não sistemática, porém, consistente. Houve um processo de reflexão e de modificação na sua execução.

Nossa abordagem metodológica partiu da busca por modelos a serem seguidos e permitiu que os participantes o fizessem de maneira reflexiva. Optamos por comparar o parâmetro do tempo nas gravações por ser mais facilmente mensurado por softwares de análise de gravações. A observação dos modelos pelo site de compartilhamento youtube espelha uma realidade. Por ser extremamente acessível, faz parte do cotidiano dos estudantes de música. 


\begin{tabular}{|c|c|c|c|}
\hline Participante & Idade/Sexo & $\begin{array}{c}\text { Nível acadêmico } \\
\text { Graduação } \\
\text { (Bacharelado) }\end{array}$ & $\begin{array}{c}\text { Nível acadêmico } \\
\text { Pós-Graduação } \\
\text { (Mestrado e Doutorado) }\end{array}$ \\
\hline $\mathbf{1}$ & $23 / \mathrm{M}$ & $8^{\circ}$ semestre (último) & -- \\
\hline $\mathbf{2}$ & $23 / \mathrm{M}$ & $3^{\circ}$ semestre & -- \\
\hline $\mathbf{3}$ & $20 / \mathrm{F}$ & $7^{\circ}$ semestre & Mestre \\
\hline $\mathbf{4}$ & $25 / \mathrm{M}$ & -- & $2^{\circ}$ ano do Mestrado \\
\hline $\mathbf{5}$ & $23 / \mathrm{F}$ & -- & -- \\
\hline $\mathbf{6}$ & $24 / \mathrm{M}$ & $6^{\circ}$ semestre & -- \\
\hline $\mathbf{7}$ & $24 / \mathrm{F}$ & Bacharel & $1^{\circ}$ ano do Doutorado \\
\hline $\mathbf{8}$ & $26 / \mathrm{F}$ & -- & Mestre \\
\hline $\mathbf{9}$ & $25 / \mathrm{F}$ & -- & \\
\hline
\end{tabular}

Tabela 4 - Informações sobre os participantes do segundo delineamento. Fonte: Acervo de Stefanie Freitas e Cristina Capparelli Gerling.

A análise dos dados pôde comprovar alguns dos aspectos sobre a condução do tempo entre as gravações e, dessa forma, conseguimos obter gráficos para melhor visualizar os resultados. Por meio desses resultados e dos depoimentos, que auxiliaram na interpretação dos gráficos, pudemos perceber o tipo de influência que cada gravação exerceu sobre cada participante. É pertinente salientar que procuramos respeitar a individualidade e a diversidade de reações de cada um dos sujeitos dessa pesquisa. Foi muito instrutivo e gratificante verificar como estudantes do bacharelado constroem sua personalidade artística individual, um requisito indispensável para se destacar em sua profissão.

\subsection{SEGUNDO DELINEAMENTO: ALUNOS DE DIVERSOS NÍVEIS ACADÊMICOS}

Neste projeto, realizamos um estudo empírico com nove participantes voluntários em níveis acadêmicos distintos e que estudavam ou já haviam estudado graduação/pós-graduação na UFRGS (vide Tabela 4).

Foram investigadas as estratégias de estudo adotadas para a realização das sobreposições rítmicas de três notas contra duas relacionadas aos elementos que influem na definição do caráter íntimo nos vinte compassos iniciais do Ponteio 46 de Camargo Guarnieri. Para compreender de forma mais eficaz o estudo das sobreposições rítmicas, realizamos um processo de modelagem induzida, escolhendo especificamente dois modelos com andamentos e inflexões rítmicas contrastantes desconhecidos pelos participantes.

O ponto de partida para as investigações iniciais sobre polirritmia foi instigado por uma carta escrita em 1964 por Roberto Szidon (19412011), pianista brasileiro então radicado na Europa, endereçada ao compositor Camargo Guarnieri (1907-1993). Szidon escreveu a carta em agradecimento por receber os Estudos do compositor, salientando "a dificuldade dura de vencer para a maioria dos pianistas" do Estudo 7 e de outras obras, como seu Ponteio 33 e 46. Ao observar as partituras do Estudo 7, dos dois ponteios mencionados, assim como das outras obras citadas na carta, como o Choros n.5 de Villa-Lobos, pudemos perceber que Szidon se refere ao fenômeno da sobreposição de figurações rítmicas, em alguns casos chamado de polirritmia e definido como a combinação simultânea de ritmos contrastantes em uma obra musical ${ }^{8}$.

Instigadas pelo comentário de Szidon sobre a dificuldade de execução das sobreposições rítmicas, decidimos abordar aspectos relacionados diretamente à realização pianística em obras selecionadas da literatura brasileira. Em estudos recentes, Gandelman e Cohen (2006; 2010; 2011) investigaram analiticamente estruturas e 
¿ Vera Blivia Perreina

PONTEIO N? 46
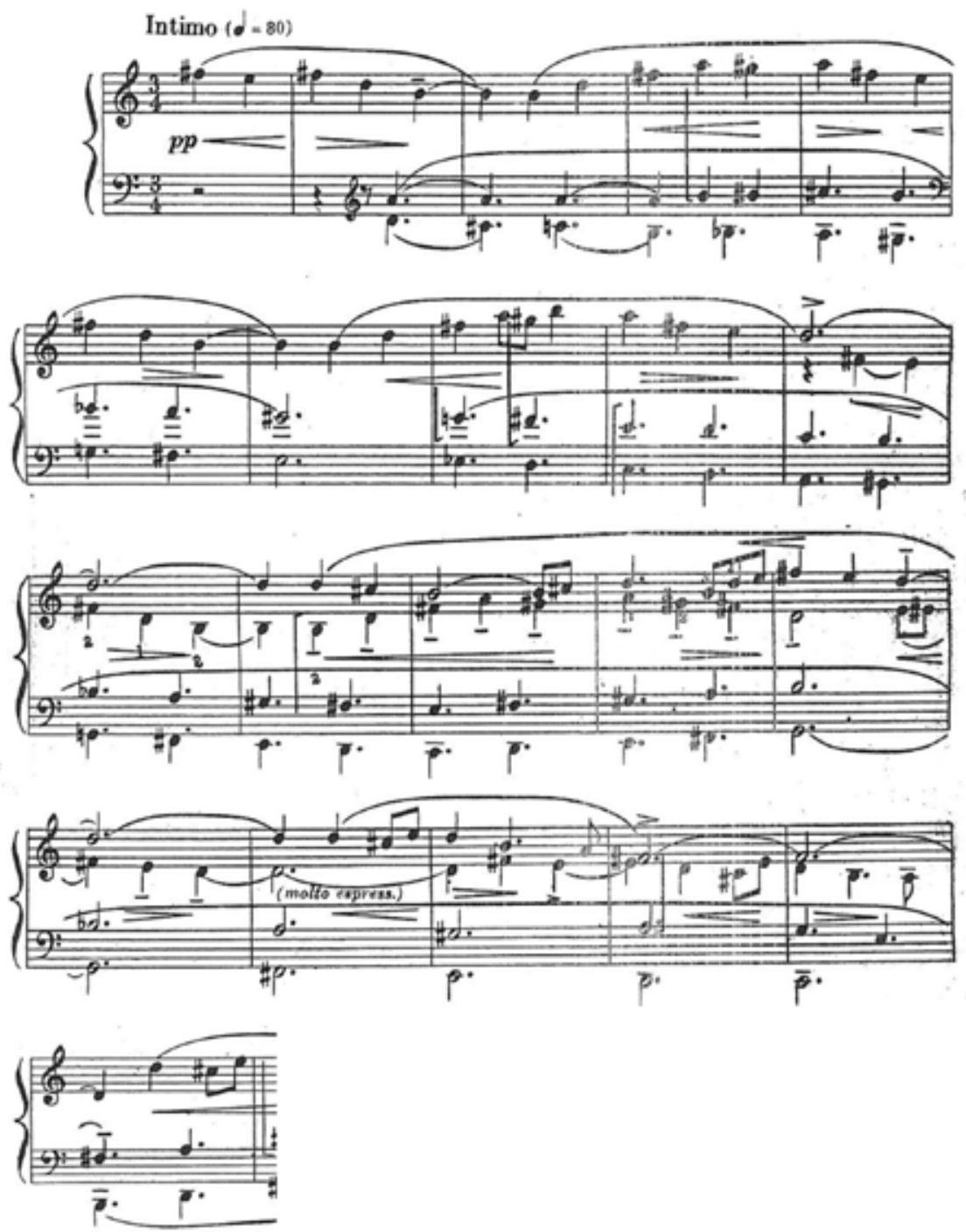

Figura 1 - Vinte compassos iniciais do Ponteio 46 de Guarnieri. Fonte: Acervo de Stefanie Freitas e Cristina Capparelli Gerling.

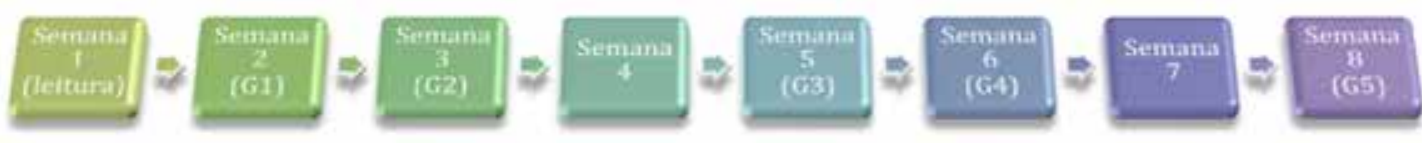

Figura 2 - Linha do tempo da coleta de dados do presente projeto.

Fonte: Acervo de Stefanie Freitas e Cristina Capparelli Gerling. 
sobreposições rítmicas na música brasileira do século XX e teceram considerações sobre ensino e aprendizagem destas estruturas. Apesar da presença constante deste fenômeno rítmico no repertório pianístico brasileiro, são poucos os estudos empíricos que tratam da complexidade rítmica como um elemento vital na construção e realização de uma interpretação de nível de excelência, tanto em interpretações de artistas consagrados quanto na formação de profissionais.

Para esta investigação escolhemos os vinte compassos iniciais do Ponteio 46 citado na carta de Szidon a Guarnieri. No decorrer desse Ponteio, as vozes superiores são articuladas por semínimas e as inferiores em semínimas pontuadas criando um agrupamento de três notas contra duas em cada compasso. Comumente descrito como "três contra dois", escolhemos esse padrão para dar início ao estudo empírico das sobreposições rítmicas, mencionado como uma dificuldade para todos os pianistas na carta de Szidon a Camargo Guarnieri. Nesse Ponteio, o compositor requer o caráter Íntimo para sua execução, sugerindo 80 batidas por minuto para a semínima. Para esta investigação selecionamos os vinte compassos iniciais, ou seja, até o acorde de Si menor no qual a seção cadencia (Vide Figura 1).

Os participantes receberam partituras contendo a primeira página da obra escolhida e não receberam orientação de seus professores na preparação dos vinte compassos iniciais do Ponteio 46, tendo em vista que a tarefa se constituiu de uma aprendizagem baseada em escuta e imitação de gravações previamente determinadas.

No contato inicial, investigamos quais gravações da obra os participantes conheciam e, desta forma, escolhemos duas gravações desconhecidas por eles a partir de dois critérios: andamentos e inflexões rítmicas contrastantes. Foram selecionadas duas gravações disponíveis no mercado, uma da Summit Records de 1999 e outra da Naxos de 2013.

A preparação do trecho foi monitorada por oito semanas através de cinco coletas que incluíram gravações em formato MIDI no Disklavier Yamaha DKC-800 e cinco entrevistas semiestruturadas gravadas em aparelho de áudio. As cinco gravações (G) foram seguidas das cinco entrevistas: G1 (leitura do trecho do Ponteio), G2 (imitação do Modelo 1), G3 (gravação com as próprias ideias interpretativas dos participantes), G4 (imitação do Modelo 2), G5 (gravação com as próprias ideias interpretativas dos participantes). Podemos visualizar o procedimento metodológico da coleta de dados deste experimento através da linha do tempo apresentada na Figura 2.

Uma vez coletados os dados, isto é, realizadas as gravações e entrevistas, as análises basearamse nos relatos dos participantes e na verificação das flutuações de tempo, ou seja, na análise do andamento e das inflexões rítmicas. Foi utilizado novamente o software Sonic Visualiser. A partir desses perfis traçados, surgiu a nossa hipótese de que a manipulação dos parâmetros temporais é imprescindível na definição do caráter de uma obra. Apesar dos parâmetros relacionados ao tempo terem sido escolhidos para análise neste experimento, os participantes foram estimulados durante as entrevistas a refletir sobre quaisquer parâmetros que julgassem importantes para a definição do caráter da obra escolhida.

Tanto nas gravações dos participantes quanto dos modelos assinalamos uma batida para cada colcheia (BPM) a fim de estabelecer as durações entre cada uma delas e, desta forma, compreender com maior grau de precisão a manipulação das inflexões rítmicas. A escolha da colcheia sobre a semínima comprovou ser eficaz. Com o programa Excel, construímos gráficos para representar as diferenças de andamento e para sobrepor as linhas da condução do tempo e as inflexões rítmicas de cada gravação. Isto tornou possível a comparação entre os participantes e os profissionais.

\subsubsection{DISCUSSÃO DOS CASOS}

No Gráfico 3, explicitamos as diferenças temporais entre as duas gravações dos dois modelos. Como anteriormente mencionado, o Modelo 1 apresenta uma interpretação caracterizada por um andamento mais lento (vide a linha verde não alcançar 200 BPM em colcheias - eixo vertical) e pela retenção no tempo (vide picos baixos da linha verde). E, por ter sido escolhida como uma gravação com características opostas, a interpretação do Modelo 2 é caracterizada por um andamento mais rápido (vide linha vermelha ultrapassando 200 BPM em colcheias - eixo vertical) e por uma condução que enfatiza impulsos constantes para frente (vide os picos altos da linha vermelha). 


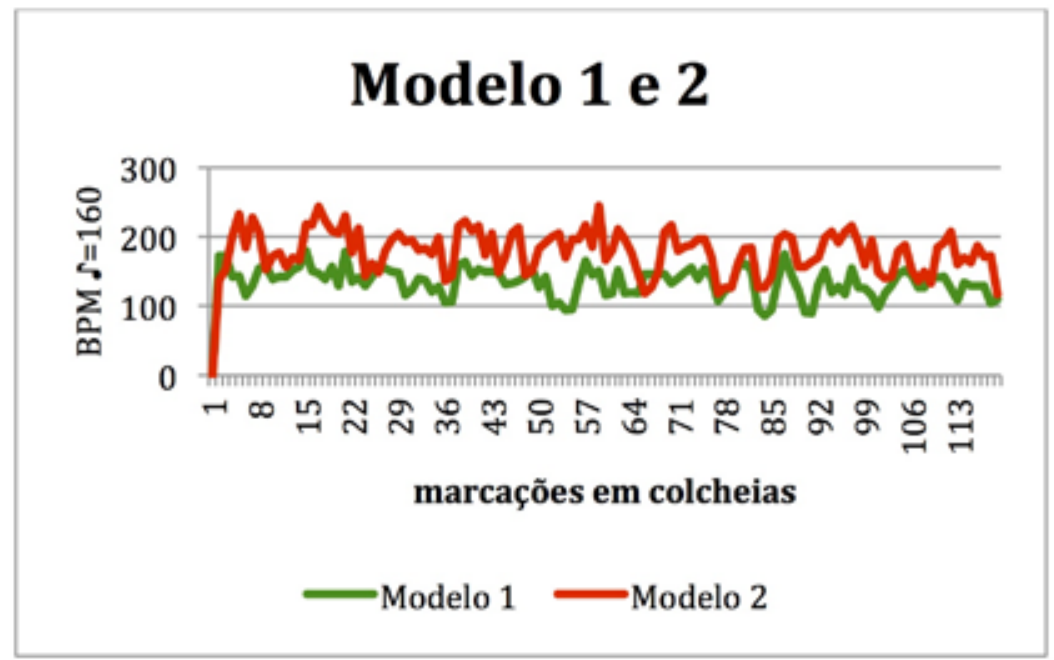

Gráfico 3 - Linha de condução do tempo dos Modelos 1 e 2.

Fonte: Acervo de Stefanie Freitas e Cristina Capparelli Gerling.

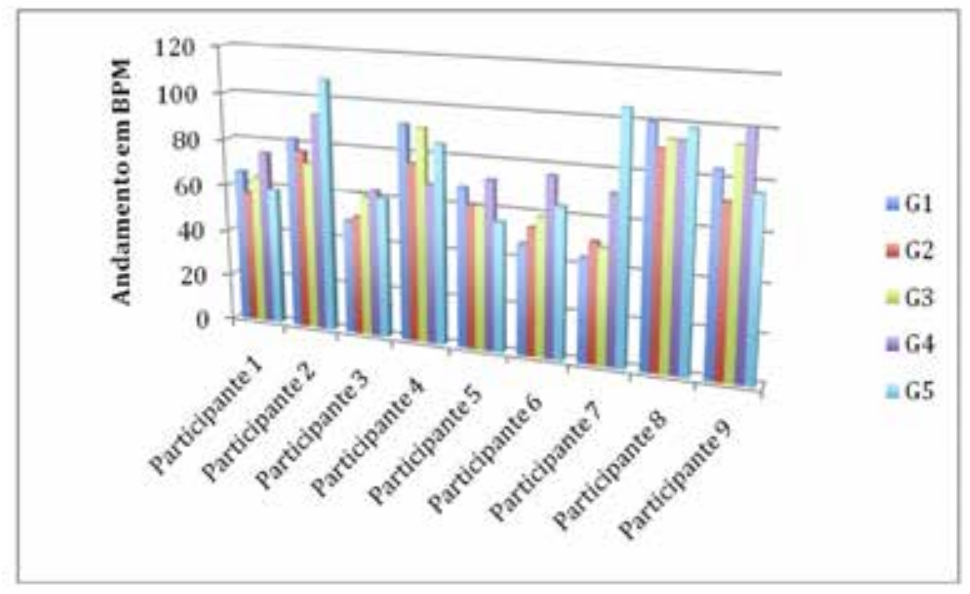

Gráfico 4 - Gráfico com os andamentos das cinco gravações de cada participante. Fonte: Acervo de Stefanie Freitas e Cristina Capparelli Gerling. 
Corrigir no quadro: Modelos 1 e 2 (no plural)

A partir dessas características extraídas dos modelos, pudemos analisar as gravações dos nove participantes relacionadas aos processos de modelagem realizados neste experimento. Os nove participantes apresentaram mudanças perceptíveis de andamento como reflexo do processo de modelagem (vide Gráfico 4).

Para comprovar as possíveis influências, relacionamos as informações contidas no Gráfico 4 com os relatos concedidos pelos participantes em relação aos parâmetros que cada um afirmou ter modificado devido à influência de ambos os modelos. A análise dos dados revelou alguns dos aspectos sobre o andamento e condução do tempo de todas as gravações e, dessa forma, conseguimos obter gráficos para melhor visualizar os resultados. Por meio desses resultados e dos depoimentos, que auxiliaram na interpretação dos gráficos, pudemos perceber o tipo de influência que cada modelo exerceu sobre cada participante e como esse processo se relacionou com a execução das figurações rítmicas e com a definição do caráter. Apesar dos parâmetros relacionados ao tempo terem sido escolhidos para análise neste experimento, os participantes foram estimulados a refletir sobre quaisquer parâmetros que julgassem importantes para a definição do caráter da obra escolhida.

Ao observar como cada participante entendeu seus processos de absorção e consequente modificação na sua execução após o trabalho realizado com cada modelo, apresentamos a seguir dados do Participante 3 e 7, dois casos opostos em relação às reações aos processos de modelagem.

O Participante 3 declarou ter tido somente uma experiência prévia com estruturas polirrítmicas em obras do seu repertório e afirmou ter tido dificuldades para realizar este tipo de padrão. Apesar disso, ele declarou que o maior desafio na leitura do Ponteio 46 foi o encaixe das décimas no fluxo do "três contra dois". Durante o processo de modelagem, suas gravações apresentaram muitas interrupções no fluxo temporal e muitas hesitações quanto às décimas que o participante não alcançava. Ele não conseguiu vencer a dificuldade de arpejar as notas do intervalo de décima e manter o fluxo no encaixe das sobreposições rítmicas.

Ao analisar as linhas de condução do tempo das suas gravações, pudemos perceber muitos picos baixos de andamento, como pode ser observado no Gráfico 5. Suas gravações demonstraram reais entraves na realização das sobreposições rítmicas vinculadas aos intervalos de décima das vozes.

O Participante 3 declarou não ter se identificado com o Modelo 2 e por isso decidiu, em sua quinta gravação, fazer um andamento "mais devagar, mais solene e com uma sonoridade mais piano". Apresentamos no Gráfico 6 suas médias de andamento durante o processo de modelagem, revelando estabilidade nas três últimas gravações (G3, G4 e G5).

Durante a coleta de dados percebemos que, neste estágio do seu desenvolvimento, ele pareceu carecer de um vocabulário técnico-musical adequado para expressar suas preferências e opiniões. Podemos concluir parcialmente que a modelagem não se mostrou evidente ou eficaz, visto que o Participante 3 não superou as dificuldades em relação às sobreposições rítmicas nem aos intervalos de décima. Ele também não apresentou mudanças significativas relacionadas ao andamento nem às inflexões rítmicas, carecendo de reflexão sobre os parâmetros que poderiam auxiliar na definição de íntimo em sua interpretação.

O Participante 7 relatou não ter dificuldades com as sobreposições rítmicas, mas demonstrou se sentir bastante frustrado por não alcançar as notas dos intervalos de décima como gostaria. Ele se identificou com a interpretação do Modelo 1 e declarou: "Eu [es]tou mais confiante porque eu concordo com o modelo! É muito ruim quando a gente lê uma peça, ouve uma gravação e pensa 'caramba, por que é tão diferente do que eu entendi?' e eu gostei e me deu mais confiança!". Ao ser questionado sobre as inflexões rítmicas do Modelo 1, ele explicou: "Os rubatos dele faziam tanto sentido pra mim que eu não parei pra imitar igualzinho, sabe, não fiquei calculando; fazia sentindo pra mim, então continuei fazendo do jeito que eu [es]tava fazendo!". Sobre as suas dificuldades e a questão do alcance das décimas, ele relatou compensar o seu impedimento com uma intenção deliberada na expressividade ao decidir realizá-las em suaves arpejos. O participante comentou também sobre sua ideia de caráter após a imitação do primeiro modelo: "muito intimista, muito triste, muito recolhido". 


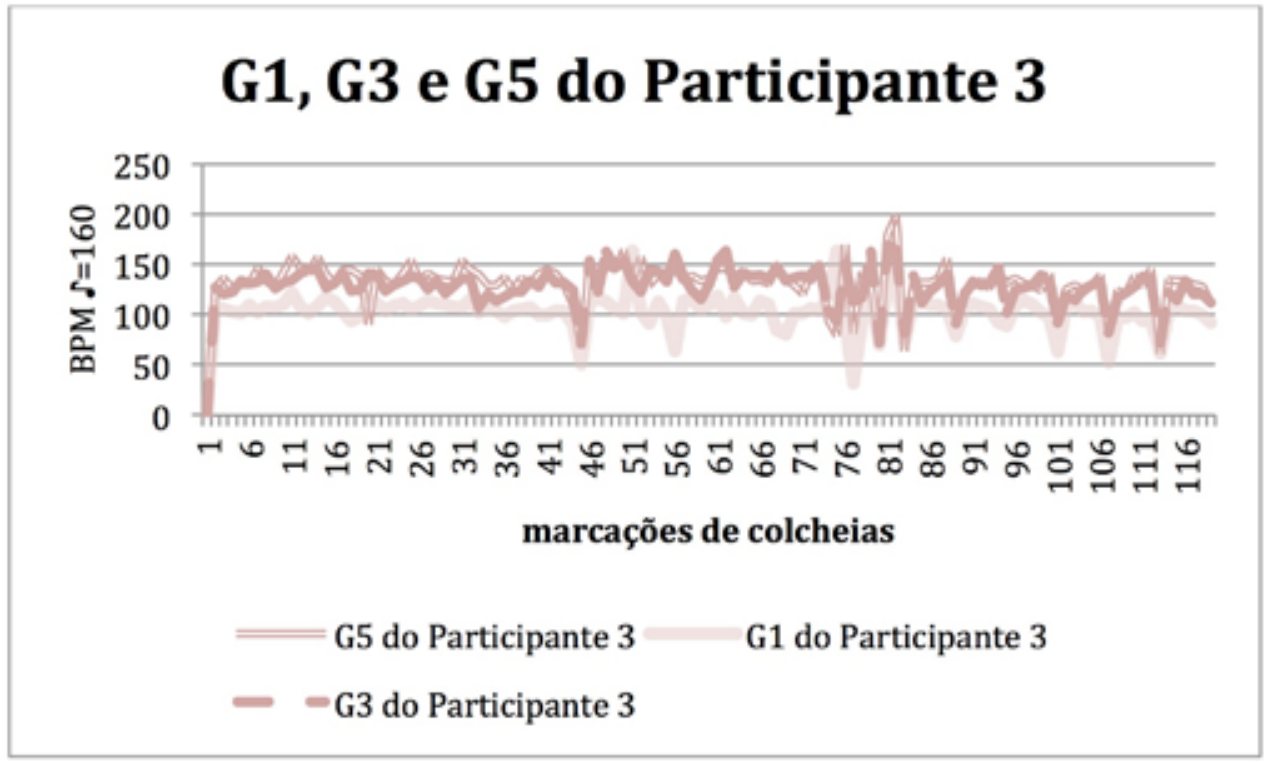

Gráfico 5 - Gráfico com as inflexões rítmicas das gravações do Participante 3. Fonte: Acervo de Stefanie Freitas e Cristina Capparelli Gerling.

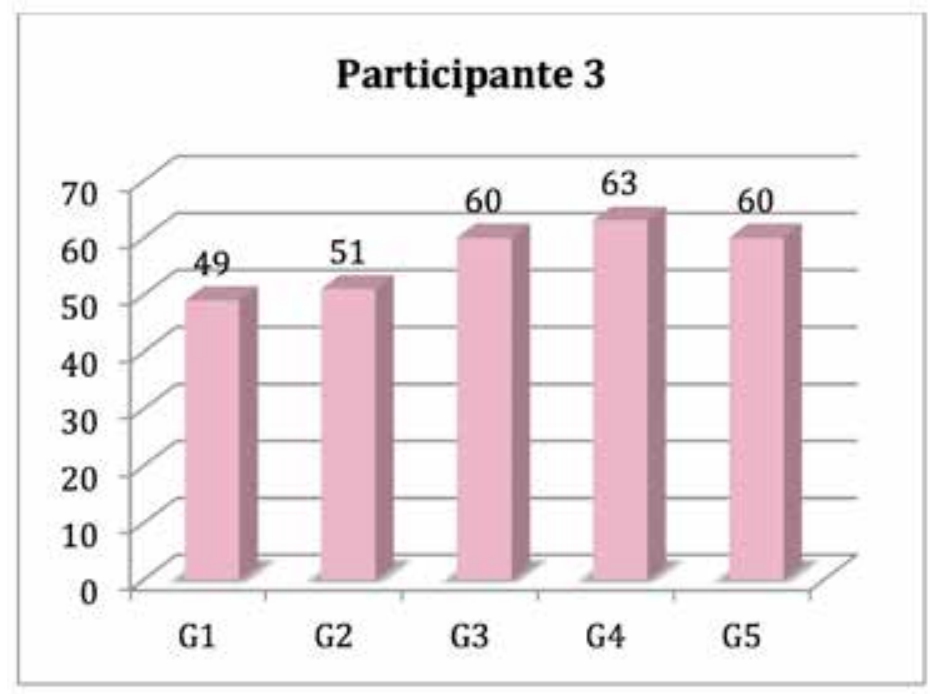

Gráfico 6 - Gráfico com os andamentos das gravações do Participante 3.

Fonte: Acervo de Stefanie Freitas e Cristina Capparelli Gerling. 
Tendo demonstrado sua identificação com o Modelo 1, deixou-se influenciar também pelo Modelo 2. Consequentemente, esta identificação operou mudanças significativas em sua maneira de manipular a condução do tempo. Em sua quarta gravação (G4), ao imitar o Modelo 2, ele afirmou não concordar com a precisão do tempo dessa interpretação, pois não conseguiu perceber o íntimo caracterizado por um andamento rápido com poucas inflexões rítmicas, em sua percepção. Também relatou ter tentado tocar as décimas juntas pela primeira vez por influência do segundo modelo, passando várias notas da mão esquerda para a mão direita para que as décimas soassem juntas. Apesar do esforço, ele contou que fez "escolhas estranhas de dedilhado" para tentar imitar o modelo e, dessa forma, se sentiu incomodado e apresentou vários erros durante a sua imitação (G4). Mas em sua quinta gravação (G5), esse participante afirmou ter buscado "um clima mais alto-astral". Sobre isso, ele afirmou: "[as mudanças] têm a ver principalmente com o andamento, eu me sinto mais cativado pela interpretação do Modelo 2".

Podemos perceber através do Gráfico 7 e 8 que os dois modelos exerceram igual importância tanto para a manipulação do tempo no que se refere às sobreposições rítmicas quanto ao andamento e ao caráter solicitado pelo compositor. Em sua última entrevista, ele afirmou taxativamente que o clima do íntimo iria depender dos seus próprios sentimentos no momento da performance. Tanto suas médias de andamento quanto suas inflexões rítmicas comprovam a influência inquestionável da modelagem, como pode ser visto nos gráficos 7 e 8 .

Nossa premissa inicial previu que as imitações dos modelos refletiriam as mudanças exemplificadas nesses dois casos individuais em relação ao tempo e que elas seriam absorvidas em alguma medida. Essa absorção se traduziria em traços detectáveis e passíveis de serem demonstrados através de gráficos. Entre esses traços, previmos que as sobreposições rítmicas seriam integradas às estratégias de manipulação de parâmetros temporais que asseguram a definição e projeção do caráter íntimo solicitado pelo compositor. Além de constatarmos que os participantes se mostraram receptivos não somente ao processo de modelagem, mas principalmente às reflexões suscitadas pelo processo para a criação de ideias próprias em suas performances, foi possível observar também que cada participante reagiu de acordo com seu nível de adiantamento e de conhecimento musical e instrumental. O segundo experimento mostrou que a imitação do modelo está contingenciada às experiências prévias de quem tenta imitar, ou seja, não há possibilidade de cópia e sim o incremento no nível de reflexão sobre processos individuais de aprendizagem.

\section{CONSIDERAÇÕES FINAIS}

Os estudantes de música, assim como jovens profissionais da área, costumam ter preferências por um ou outro instrumentista, vão assistir a seus concertos quando possível e observam, mesmo que não sistematicamente, aspectos técnicos ou expressivos de seus ídolos. Nossa abordagem metodológica partiu dessa busca por modelos a serem seguidos e permitiu que os participantes dessas duas investigações o fizessem de maneira individualizada e reflexiva.

A premissa essencial do nosso projeto tem sido a compreensão de significados e conceitos extraídos diretamente da prática musical dos participantes comoindivíduos que buscam o mais alto nível de realização pianística e artística. A abordagem qualitativa privilegiou o nível subjetivo dessa pesquisa, deslocando o foco, a realidade, os significados atribuídos pelos participantes juntamente com suas intenções e ações. Todavia, a maioria das pesquisas sobre a prática instrumental na literatura internacional tende a não discutir as abordagens críticas e reflexivas dos desafios enfrentados por estudantes e jovens profissionais em seu estudo diário.

A proposição dessa metodologia hipotetizou que a modelagem estimula a ampliação de recursos expressivos e o desenvolvimento de uma voz artística própria para cada um dos participantes. 0 respeito aos sujeitos e aos objetos de pesquisa são condições necessárias para alcançar resultados confiáveis. Essas investigações deram importância à observação sistemática dos processos de estudo e dos produtos da performance musical.

Cada participante direcionou a escuta do modelo de acordo com suas próprias preocupações e objetivos individuais, demonstrando maturidade ao refletir sobre seu próprio desempenho e sua produção. Os desafios gerados pelo processo de imitação 


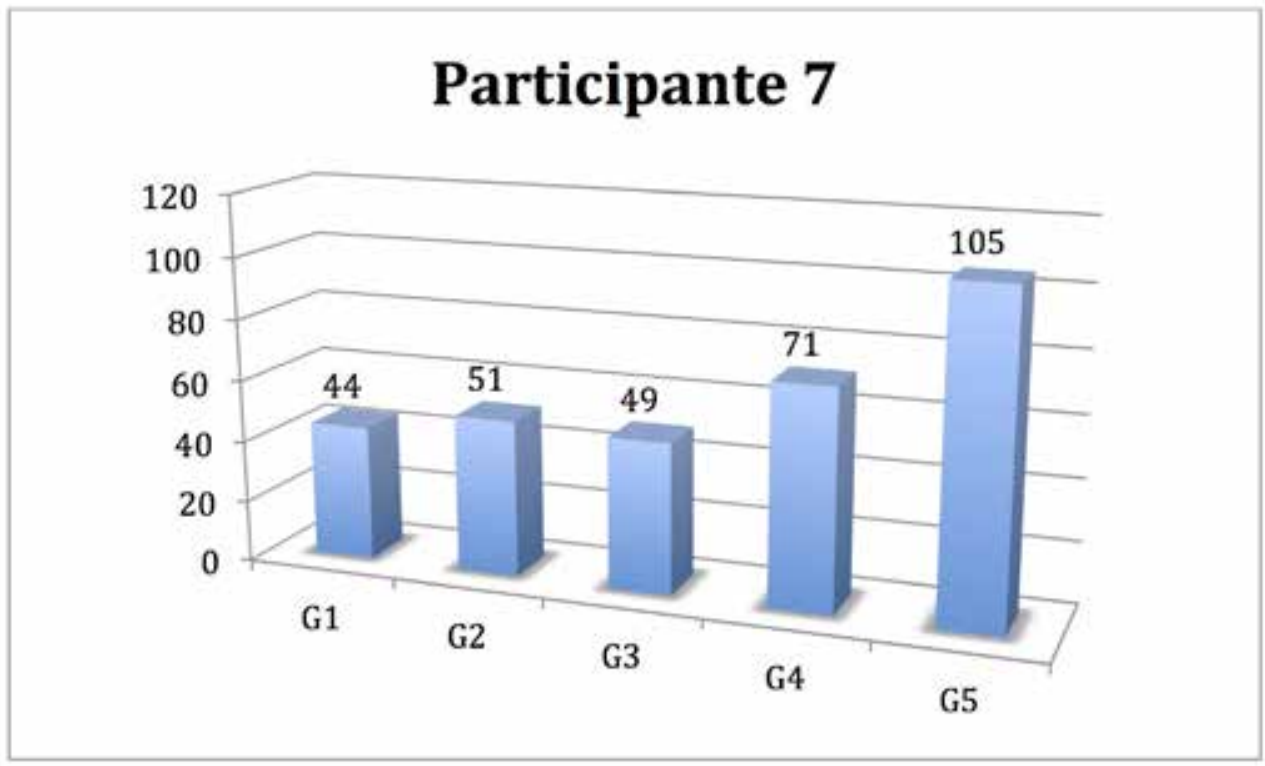

Gráfico 7 - Gráfico com os andamentos das gravações do Participante 7. Fonte: Acervo de Stefanie Freitas e Cristina Capparelli Gerling.

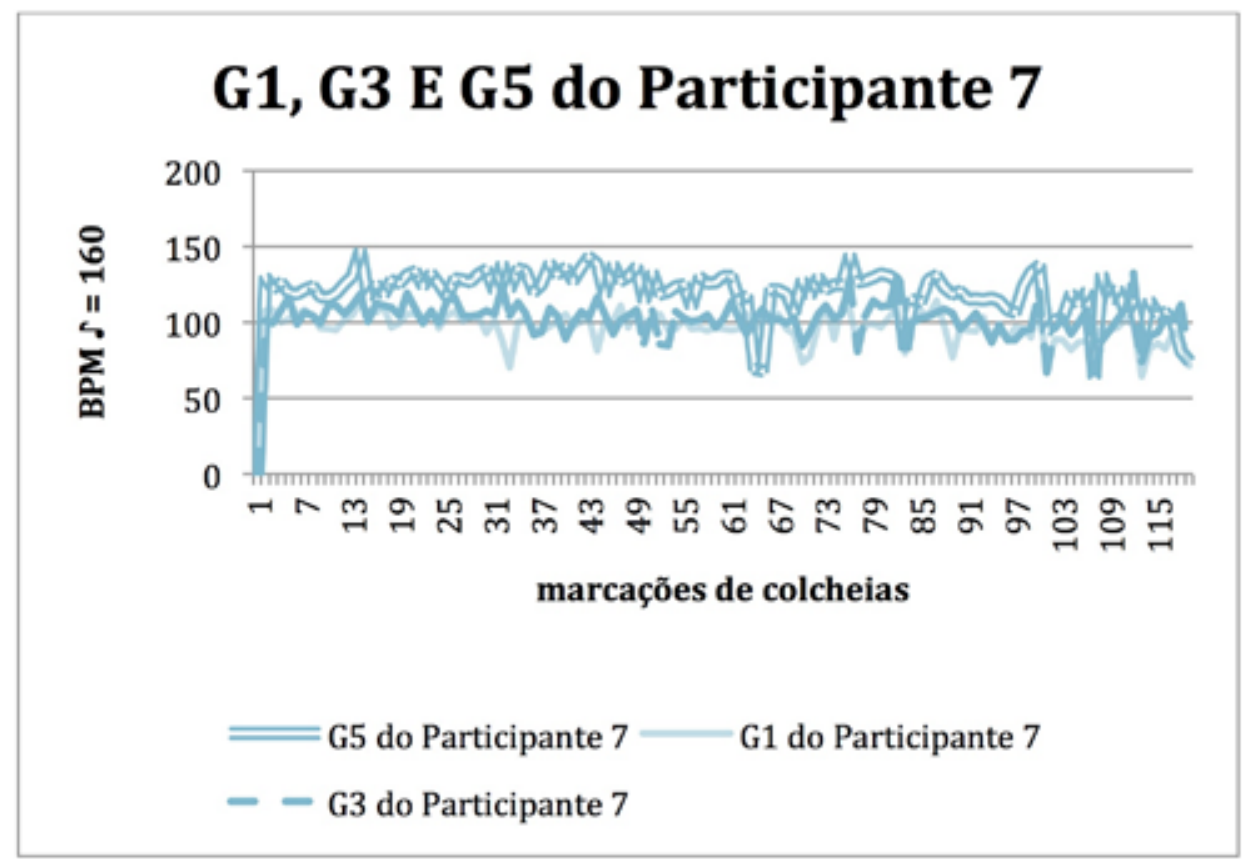

Gráfico 8 - Gráfico com as inflexões rítmicas das gravações do Participante 7. Fonte: Acervo de Stefanie Freitas e Cristina Capparelli Gerling. 
ofereceram aos participantes a possibilidade de repensar suas estratégias de estudo juntamente com a amplitude e aplicabilidade dos seus recursos expressivos. E, sobretudo, permitiram que eles refletissem sobre a sua individualidade e criatividade como intérpretes. O método mostrouse pertinente para responder às questões de pesquisa suscitadas anteriormente e, dessa forma, confirmou nossa hipótese: a modelagem promoveu o incremento e a ampliação no vocabulário de recursos expressivos para a realização dos trechos escolhidos, fomentou o desenvolvimento de uma autonomia e individualidade em suas interpretações e, como parte mais enriquecedora do processo, incentivou a audição e reflexão crítica sobre seus processos de estudo.

\section{NOTAS}

1. “(...) imitation is a necessary first stage in a development that, ideally, should lead to assimilation of the imitated patterns into a rich expressive vocabulary from which new and original patterns and combinations may emerge" (REPP, 2000, p.208).

2. "Conscioulsy entering into the master's way of designing, the students add to her range of possible performance and extends her freedom of choice" (SCHÖN, 1987, p.121).

3. Traduzimos o termo modeling da literatura internacional como modelagem. Albert Bandura (1979), da área da psicologia social e cognitiva, utiliza o termo modelagem ou modelação para explicar os processos e padrões de comportamento de um indivíduo através da observação e imitação de outros.

4. "We must recognize the amazing power of the infant who absorbs everything in his surroundings and add to his knowledges" (KENDALL, 1985, p.12).

5. Para preservar o anonimato, cada participante escolheu um nome fictício para esta investigação.

6. Sonic Visualiseré um programa atual e eficaz para análise e comparação de gravações desenvolvido no Centre for Digital Music, Queen Mary, University of London. Está disponível para download gratuito no site http://www.sonicvisualiser.org

7. Excel é um editor de planilhas construído pela Microsoft que permite a construção de gráficos. Com esse programa, construímos gráficos para sobrepor e comparar as linhas da condução do tempo de cada gravação analisada.

8. RANDEL, Don Michael (Ed.). Harvard Concise Dictionary of Music. Harvard University Press, 1978 , p. 397.

\section{REFERÊNCIAS}

BARTEN, S. Speaking of music: The use of motoraffective metaphors in music instruction. Journal of Aesthetic Education, Vol. 32, No. 2 (Summer, 1998), p. 89-97, 1998.

BERLINER, P. F. Thinking in Jazz: The Infinite Art of Improvisation. Chicago, IL: Chicago University Press, 1994.

DICKEY, M. A Review of Research on Modeling in Music Teaching and Learning. Bulletin of the Council for Research in Music Education, 113, p. 27-40, 1992.

FREITAS, S. Modelagem como estratégia para o desenvolvimento de recursos expressivos na performance pianística: três estudos de caso. Tese de doutorado, UFRGS, 2013.

GANDELMAN, S.; COHEN, S. "A Cartilha Rítmica para Piano de Almeida Prado: vertentes pedagógicas". XV Congresso da Associação Nacional de Pesquisa e Pós-Graduação em Música, 2006, Rio de Janeiro. ANPPOM, v. 1, 1015, 2006.

"Polirritmia no ensino do piano". $\quad \mathbf{X X}$ Congresso da Associação Nacional de Pesquisa e Pós-Graduação em Música, 2010, Florianópolis. ANPPOM, v.1, 10-18, 2010.

"O estudo da polirritmia em Ernst Widmer". XXI Congresso da Associação Nacional de Pesquisa e Pós-Graduação em Música, 2011, Uberlândia. ANPPOM, v. 11, 1-8, 2011.

JOHNSON, Peter. The legacy of recordings. In RINK, John (Ed.). Musical Performance: a guide to understanding. Cambridge University Press, 2002.

KENDALL, J. The Suzuki Violin Method in American Music Education. Summy-Bichard Inc, Florida, 1985. 
LINDSTRÖM, E.; JUSLIN, P.; BRESIN, R,; WILLImon, A. "Expressivity comes from within your soul": A questionnaire study of music students' perspectives on expressivity. Research Studies in Music Education, 20, p. 23-47, 2003.

MILLS, E; MURPHY, T. C. (Ed.). The Suzuki Concept: An introduction method for early music education. California: Diablo Press, 1973.

REPP, B. Pattern typicality and dimensional interactions in pianists' imitation of expressive timing and dynamics. Music Perception, 18, p. 173-211, 2000.

ROSENTHAL, R. The relative effects of guided model, model only, guide only, and practice only treatments on the accuracy of advanced instrumentalists' musical performance. Journal of Research in Music Education, Vol.32/4, p.265273, 1984.

ROSENTHAL, R.; WILSON, M.; EVANS, M.; GREENWALT, L. Effects of Different Practice Conditions on Advanced Instrumentalists' Performance Accuracy. Journal of Research in Music Education, Winter 1988 vol. 36 no. 4 250257, 1988.

SCHÖN, D. A. Educating the reflective practitioner. Jossey-Bass, San Francisco, 1987.

SLOBODA, J. A. The communication of musical metre in piano performance. Quaterly Journal of Experimental Psychology, 35A, p.337-396, 1983.

. "The acquisition of musical performance expertise: Deconstructing the 'Talent' Account of Individual Differences in Musical Expressivity". In The Road to excellence: The acquisition of expert performance in the arts and sciences, sports and games editado por K.A. Ericsson, 107126. Mahwah, NJ: Lawrence Erlbaum Associates, 1996.

TAIT, M. J. Teaching strategies and styles. In: COWELL, R. (Ed.) Handbook of research on music teaching and learning. New York: Schirmer. 1992.

WOODY, R. The relationship between explicit planning and expressive performance of dynamic variations in an aural modeling task. Journal of Research in Music Education, p. 47-331, 1999.
--_-_-_-_ Learning expressivity in music performance: an exploratory study. Research StudiesinMusicEducation, Vol.14/1, 2000.

\section{Sobre as autoras}

\section{Stefanie Grace Azevedo de Freitas}

É pianista atualmente realizando estágio pósdoutoral financiado pelo PNPD/CAPES e orientado pela Profa. Dra. Cristina Capparelli Gerling na UFRGS, instituição na qual obteve em 2013 o título de Doutora em Música na subárea das Práticas Interpretativas/Piano. Obteve o grau de Mestre em Música na mesma instituição, é Bacharel em Instrumento/Piano pela UFPE.

\section{Cristina Maria Pavan Capparelli Gerling}

Pianista e pesquisadora, concilia uma agenda intensa de atividades artísticas, docentes e de pesquisa. Professora Titular na Universidade Federal do Rio Grande do Sul, é orientadora de mestrado e doutorado no Programa de Pósgraduação em Música. Suas gravações refletem seu interesse pelo repertório brasileiro e latinoamericano. Frequentemente é convidada para ministrar aulas e conferências em instituições no Brasil e no exterior. Resultados parciais de suas pesquisa podem ser averiguados em www.ufrgs. $\mathrm{br} / \mathrm{gppi}$. 